\title{
Eucalyptus Tree Production in Wolayita Sodo, Southern Ethiopia
}

\author{
Molla Mekonnen Alemu \\ University of Leicester, Leicester, UK \\ Email: mollamekonnen@gmail.com
}

How to cite this paper: Alemu, M.M. (2016) Eucalyptus Tree Production in Wolayita Sodo, Southern Ethiopia. Open Access Library Journal, 3: e3280.

http://dx.doi.org/10.4236/oalib.1103280

Received: December 6, 2016

Accepted: December 23, 2016

Published: December 26, 2016

Copyright ( $\odot 2016$ by author and Open Access Library Inc.

This work is licensed under the Creative Commons Attribution International License (CC BY 4.0).

http://creativecommons.org/licenses/by/4.0/ (c) (i) Open Access

\begin{abstract}
Trees form an important element for the livelihoods of many in different parts of the world. Provision of oxygen to the atmosphere, combating climate change, improving microclimates, soil and water conservation and the support to wildlife are among the social, ecologic and economic values which substantiate their importance to our environment. Eucalyptus known to have more than 700 genus is believed to be a native tree species of Australia. The tree was introduced to Ethiopia during the time of Emperor Minilik. The tree has a strong potential to adapt in various ecological settings and from fertile to degraded lands. Its fast growing nature has also made it to be an economically viable tree species in the country. It is also the major source of fuelwood and construction materials in the country. The tree, however, due to its aggressive growth nature, has its own ecological impact on the environment as compared to other trees. It is known to consume a lot of water deep in the soil strata and has allelopathic effect which suppresses the under-growth in it. A study was done to explore its social, economic and ecological importance in Wolayita Sodo, southern Ethiopia. Interviews and related literature reviews were used as source of information. Data was then analysed through content analysis and descriptive statistics. The findings of the study showed that, the tree has played a lot in transforming the lives of producers economically. Its contribution in satisfying the household energy demands of the locality is also mentioned as one of its major benefits. However, given its wide expansion in the area in a monoculture way could cause for the degradation of other native biodiversity resources of the country. This is also exacerbated by its allelopathy nature that will restrict the opportunities of using intercropping management practices and have a diversified plantation system in a sustainable and friendly to the environment way. Thus, further detailed socio-economic and ecological studies could help to inform policy makers and environmentalists for the design of appropriate management and production strategies of the tree.
\end{abstract}




\section{Subject Areas}

Agricultural Science, Plant Science

\section{Keywords}

Eucalyptus, Trees, Ecology, Southern Ethiopia

\section{Introduction}

Trees support the survival of living organisms through soil and water conservation, carbon sequestration, nutrient recycling, ameliorating environmental pollution and by supporting the life of wildlife which form part of the ecological functions of an environment. According to the U.S. Department of Agriculture [1], "One acre of forest absorbs six tons of carbon dioxide and puts out four tons of oxygen. This is enough to meet the annual needs of 18 people."

Trees moderate the climate by regulating the impacts of wind speed, runoff, and sun. Since trees serve as a physical barrier to a speedy wind, agricultural productions are also effective than farmlands devoid of trees. Trees moderate the harsh temperature of an area as they have the potential of reducing the greenhouse effect of heat intensity by retaining the carbon dioxide level at its minimum. Trees increase the organic matter content of an area as the leaf fall will help to increase the litter mass of the soil.

Many wild and domestic animals are also highly reliant on trees for their food. The animal kingdom with its wider composition of the different species and eating habits relies on the leaves, flowers, fruits, seeds, stem and the roots of plants for their survival. This process creates the enabling environment for seed dispersal, pollination and the entire plant development stages. This ecological interaction in the food chain is an important catalyst to sustain the life of humans.

From socioeconomic perspectives, trees are believed to have impact on reducing noise pollution and thereof its direct contribution to stabilizing and improving the psychology and health of humans. As a result of the aesthetic values, different landscapes are also serving as a local economic and regional economic and livelihoods development. Construction materials, household and office furniture can also be obtained from trees, provided that these resources are used and managed in a sustainable way.

It is evidenced that, more than 2 billion people of the world are highly reliant on fuelwood as their source of household energy [3], about $90 \%$ of them being from the developing world [4] (Table 1).

Eucalyptus, an Australian native tree species, coined its name from two Greek words $\varepsilon v(e u)$ "well" and $\kappa a \lambda u ́ \pi \tau \omega$ (kalýpto) "to cover", which refers to the operculum on the calyx that initially covers the flower [6]. It is a flowering plant that belongs to the family Myrtaceae under the plant kingdom. It has a diverse genus and constitutes for more than 700 species. It is also believed to be the tallest flowering plant and the height can go up to 100 meters, though there are also dwarf species in it [2] [7] [8]. 
Table 1. Area coverage of Eucalyptus plantations in some countries.

\begin{tabular}{ccc}
\hline S.N. & Country & Area under Eucalyptus (hectare) \\
\hline 1 & Brazil & $3,000,000$ \\
2 & India & $1,000,000$ \\
3 & China & 600,000 \\
4 & Portugal & 550,000 \\
5 & South Africa & 477,000 \\
6 & Spain & 396,000 \\
7 & Ethiopia & 506,000 \\
8 & Morocco & 200,000 \\
9 & Chile & 170,000 \\
10 & Australia & 125,000 \\
11 & Thailand & 100,000 \\
& Total & $6,618,000$
\end{tabular}

Source: [2] [5].

As been mentioned by Haileab [2] and other researchers, Eucalyptus trees are known to provide a wide array of goods and services namely, provision of fuelwood, charcoal, construction materials, household and farm implements, pulp, eucalyptus oil, timber and poles. As a result of the quick growth habit, the tree is turned out to be very beneficial for the production paper. The tree also has indigenous and modern medicinal values. In Ethiopia for instance, the steam from water boiled Eucalyptus globulus tree leaves are known to cure flue. Countries like Australia, Brazil, Chile, Portugal, South Africa, Spain, and Swaziland are also known for the production of Eucalyptus oil.

Eucalyptus was initially introduced to Ethiopia during the time of Emperor Minilik with the aim of satisfying the fuelwood demand of the capital and its surrounding territories. Then at latter ages the tree was disseminated in various highlands of the country and it has got its popularity as a result of its strong potential to adapt in various ecological settings and from fertile to degraded lands. Its fast growing nature has also made it to be an economically viable tree species of the country. This study was hence done in Wolayita Sodo area of Southern Ethiopia where Eucalyptus is the predominantly grown as a cash crop.

\section{Eucalyptus in Ethiopia}

The introduction of Eucalyptus tree to Ethiopia goes back to the time of Emperor Minilik II when he established the present capital of the country, Addis. With the development of the capital and other cities, he noted the shortage of fuelwood and other construction materials could hamper the development of the cities. In 1895, he then intro- 
duced Eucalyptus by making innovative administrative ways which includes providing tax relief for Eucalyptus growers and distribution of seeds and seedlings for free. The country's natural plantations could have disappeared if this alternative was not in place at that point in time [9].

Eucalyptus is an important tree in various socioeconomic dimensions of many Ethiopians. For many years, Ethiopians have been attached to it as it served by being the prime source of construction material for houses. This fast growing tree has provided goods and services that enabled livelihoods development in one way or another to different localities by providing income generation opportunities and wood products for household consumption [10].

The degradation of land resources is getting sever problem in most highlands and lowlands of Ethiopia. Though there are magnificent developments in increasing agricultural production and productivity, the forestry and the green energy sector is still lingering to bridge the energy and construction demand of the growing population. Hence, placing proper management practices for the production of fast growing trees like Eucalyptus could help to intensify the sustainable development of the nation (Table 2).

\section{Methodology}

\subsection{Description of the Study Area}

Wolayita Sodo is located in the Wolayita Zone of the Southern Nations, Nationalities and People's Regional State of Ethiopia in between $6^{\circ} 4^{\prime} \mathrm{N}$ to $7^{\circ} 1^{\prime} \mathrm{N}$ latitudes and $37^{\circ} 4^{\prime} \mathrm{E}$ to $38^{\circ} 2^{\prime} \mathrm{E}$ longitudes. The region has a total area of about $4537.5 \mathrm{KM}^{2}$ (Figure 1). The study area is located at 330 Kilometers away south of the capital Addis Ababa and 50 Kilometers from Hawassa, capital of the Regional State [11].

Table 2. Eucalyptus tree population in East Africa.

\begin{tabular}{ccc}
\hline S.N. & Countries & Eucalyptus forest (hectare) \\
\hline 1 & Ethiopia & 506,000 \\
2 & Somalia & $\mathrm{Na}$ \\
3 & Djibouti & $\mathrm{Na}$ \\
4 & Sudan & 23,000 \\
5 & Kenya & 60,000 \\
6 & Uganda & 11,000 \\
7 & Rwanda & 102,765 \\
8 & Burundi & 40,000 \\
& Total & 742,765 \\
\hline
\end{tabular}

Source: [5]. 


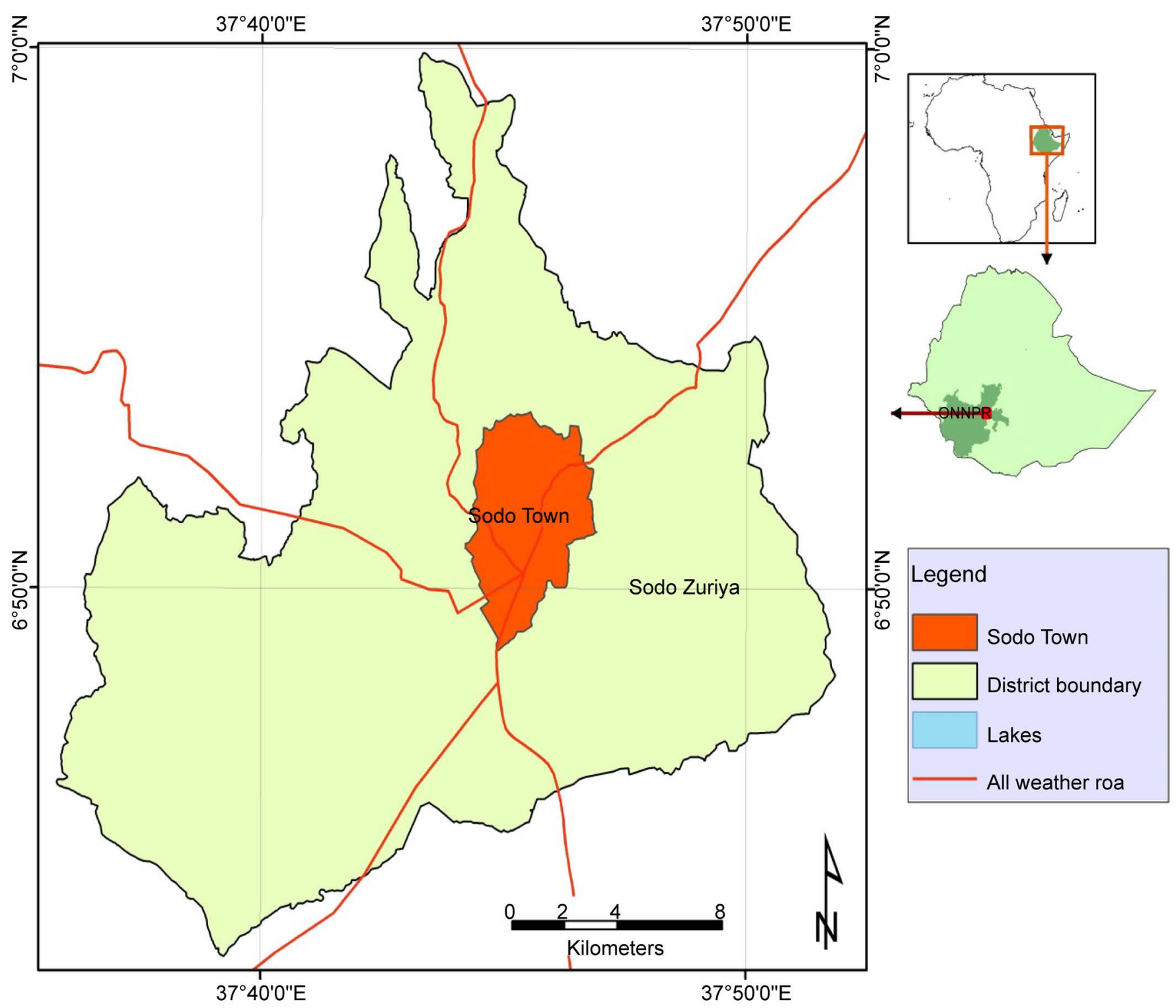

Figure 1. Location map of Wolayita Sodo [12].

\subsection{Data Collection and Analysis}

Qualitative and quantitative data was collected by making use of semi-structured interviews, discussions and review of related literature and reports. The research also deployed ground truthing so as to substantiate the information with the ground realities. 87 (13 women) community members participated in the interview and discussions. 4 concerned government staff also approached to solicit primary and secondary information. Information on the socioeconomic perceptions, ecological implications and the preference of the community towards Eucalyptus production and other related information were collected and the data was transcribed and content analysed. The quantitative information was also summarized using descriptive statistical tools like tables and figures. 


\section{Results and Discussion}

Eucalyptus has become the most planted tree of the world [13]. In Ethiopian highlands and in India for instance the tree is grown in farm and household boundaries. The tree has elongated rooting system and could have a minor chance of competing with the herbaceous shallow roots crops. When planted properly, in farmlands it will also serve as a physical barrier to lower down the effects of wind speed on farmlands and hence, will contribute for the maximization of agricultural production since evaporation rate will be reduced from plants and the surface of the soil. It is also evidenced that Eucalyptus camaldulensis strips intercropping have enhanced the production of cotton in irrigation agriculture. In waterlogged highlands of Ethiopia the production of Eucalyptus has increased land productivity without a significant effect on the availability of nutrients for the other elements of the agroforestry systems and practices [14].

Eucalyptus plantations are becoming a cash crop among the African poor by supporting income generation and provision of employment opportunities. In the highlands of Ethiopia too, Eucalyptus production has become as an alternative income source and employment opportunity [13].

In Ethiopia, 506,000 hectares of land is believed to be covered by Eucalyptus. E. globulus and $E$. camaldulensis are the main species of Eucalyptus growing in the highlands of Ethiopia. Presently, there are 55 species of Eucalyptus tree growing in Ethiopia, of which the most widespread species include Eucalyptus camaldulensis, Eucalyptus citriodora, Eucalyptus globulus, Eucalyptus regnans, Eucalyptus saligna and Eucalyptus tereticornis. In Ethiopia, socioeconomic studies on Eucalyptus production have showed as the tree is having a magnificent contribution towards household income generation than other agricultural produces [5].

Cognizant of the growing demands for household energy demand and the corresponding deforestation rate of the country many Eucalyptus plantation projects were implemented since 1980 with support from different development partners of the country. SIDA, UNSO, DANIDA, FINNIDA, World Bank and the African Development Bank being the prime donors for these initiatives. Hence, several plantations were established in the highland cities such as Debre Berhan, Gondar, Bahir Dar, Addis Ababa and Dessie [15]. Today the tree is also being widely grown in the Southern Nations and Nationalities People's Regional State and Oromia.

In Ethiopia, the socioeconomic importance of the tree can be vividly seen all the way from the capital Addis Ababa through countryside. The various construction sites in big cities of the country, the household energy demand of most Ethiopians, income generation, source of the building material for small homes to large ones and many more socioeconomic aspects of the people are highly reliant on Eucalyptus plantations.

In the study area, Wolayita Sodo, Eucalyptus trees are found being planted as boundary demarcations, home gardens, woodlots and as roadside plants. Based on the response from the respondents, it was found out as the tree population is increasing from time to time as a result of its increased contribution for household income generation, construction of houses and being major source of fuelwood (Figure 2). Due to the 
increased economic importance of the Eucalyptus in the country, the tree is serving as a major source of household income of the study area and the research has found out as the income of the Eucalyptus growers has increased consistently when compared to the previous decades (Figure 3 ).

Eucalyptus tree has a hardwood and tree is known to be one of the fastest growing trees and yield the required product within a very short period of time as compared to other trees. Findings have also showed as the tree has the highest amount of thermal energy when compared to other tree types and the thermal energy which can be generated from cow dung. According to respondents, the fuelwood from Eucalyptus is also available at an affordable price. For these very reasons, Eucalyptus fuelwood has got the highest proportion of respondent's preference in terms of household energy source of the area (Figure 4).

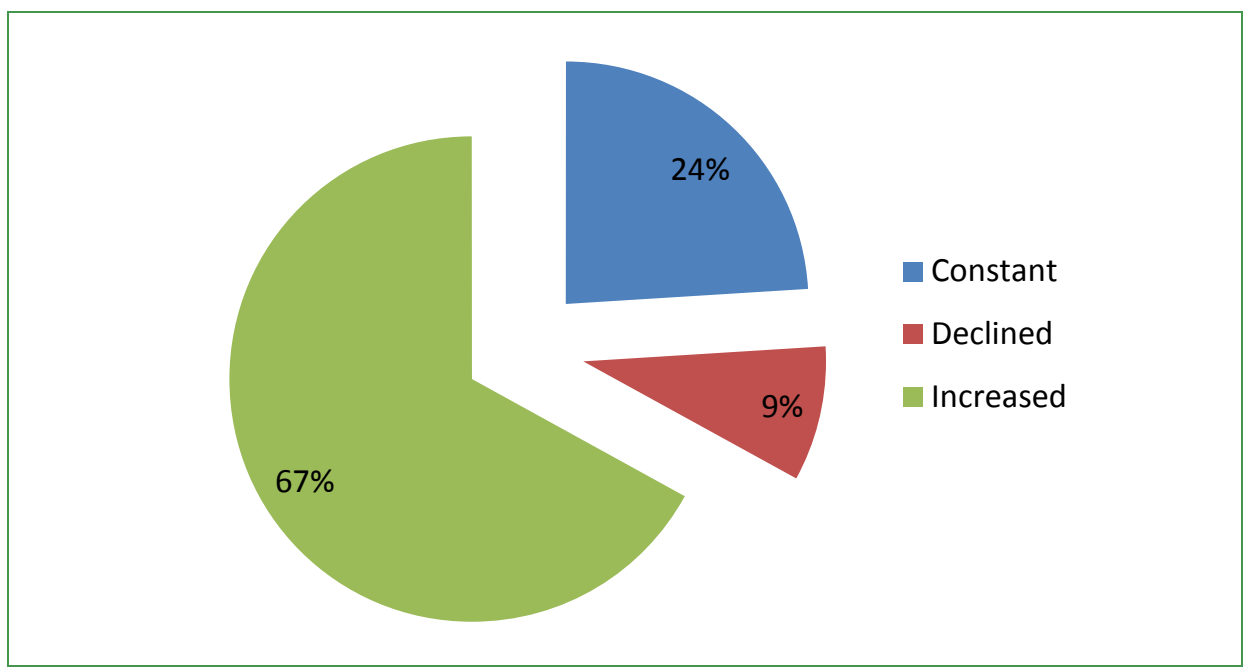

Figure 2. Perception of respondents on the trend of Eucalyptus production for the last decade.

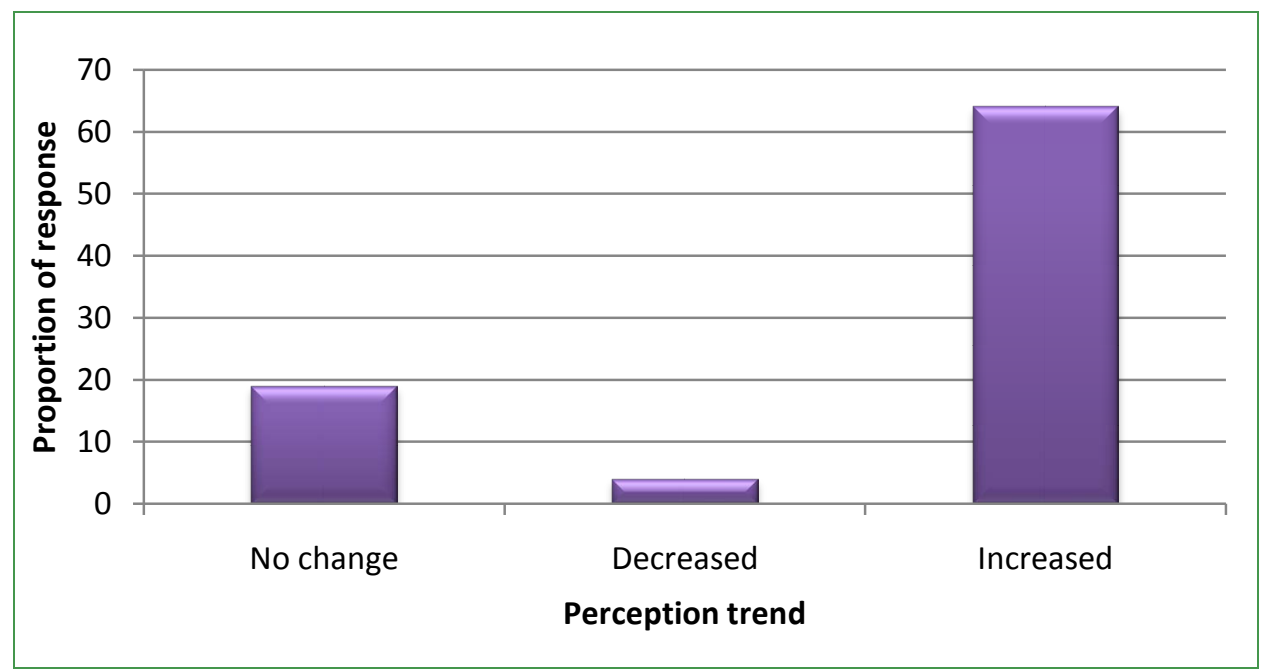

Figure 3. Perception of the current Eucalyptus producing households' income status as compared to ten years ago. 
Since the tree is known to have a long root system, growing Eucalyptus has helped the locality to generate income even under moisture stress seasons and maintain the food security status of the household.

Though the allelopathy effects of growing Eucalyptus are still a major concern, the study has revealed as growing Eucalyptus helped in moderating the climatic factors such as temperature and rainfall. In addition to this, trees grown in the farm fields during hot seasons are also serving as source of shade for humans and the livestock populations. The erosion control, windbreak and shelterbelt roles of the tree in farmlands were also mentioned as the other beneficial dimensions of the tree in maximizing other forms of agricultural production in the area.

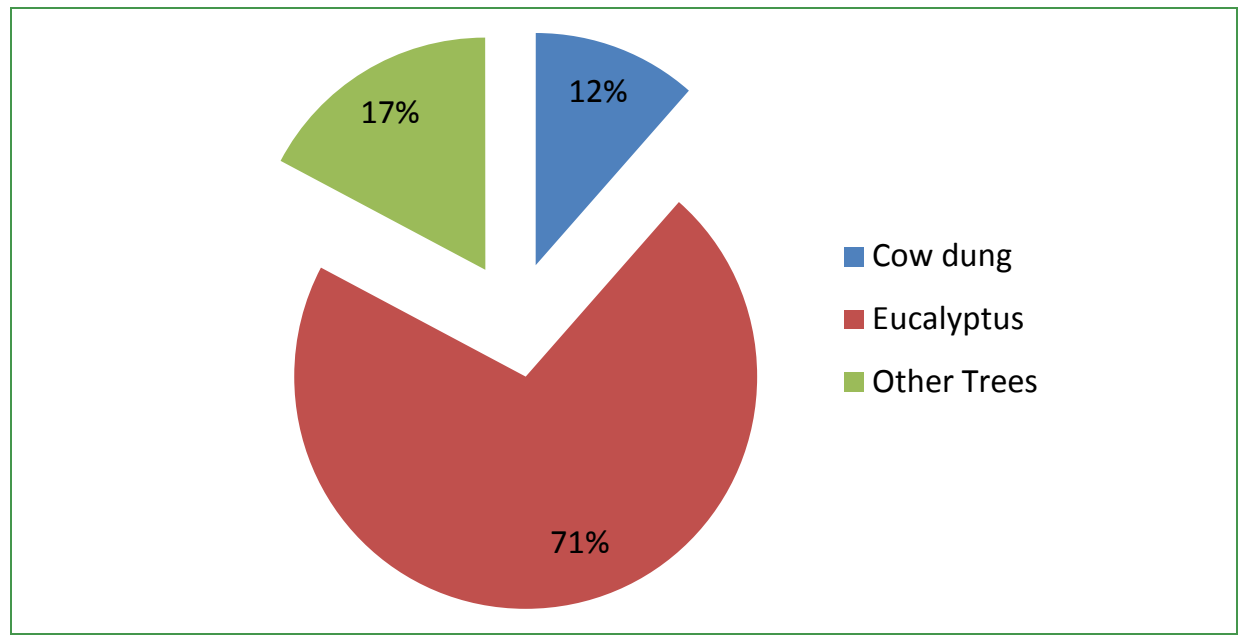

Figure 4. Preference ranking of household energy sources.

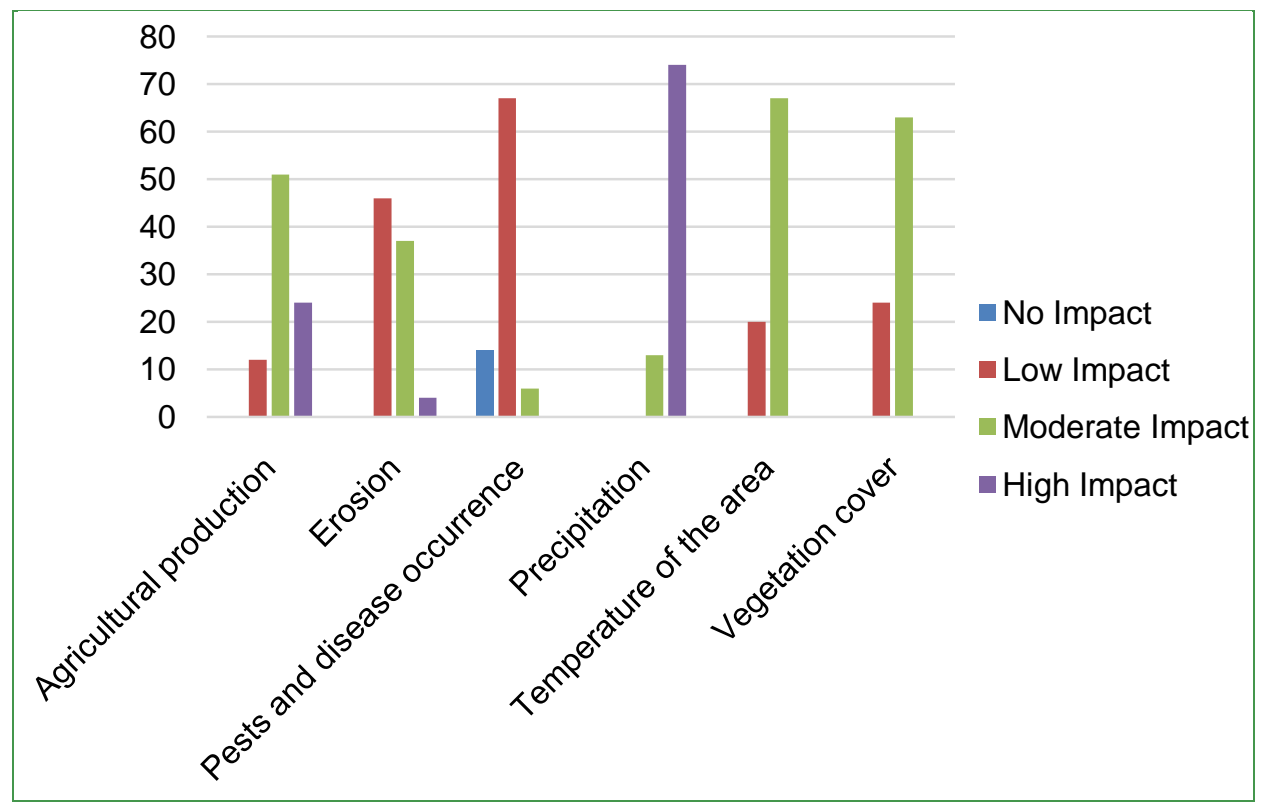

Figure 5. Perception of respondents on changes in different environmental variables since Eucalyptus production is escalated in the area (in \%). 
A study on Eucalyptus production in central Ethiopia has also showed that the fast growth nature of the tree, the increased demand of fuelwood, the high rate in biomass production, easy management requirements of the tree, the unpalatable nature of the tree for animals, adaptability to a wide range of climates and edaphic factors, increasing demand poles and timber products in the construction sector and the decline of offfarm income generation opportunities are the prominent factors that enhanced Eucalyptus production in the country [16].

It has also been reported as Eucalyptus production helped to generate a considerable amount of income than other exotic tree species and even better income was obtained from the production of the tree as compared to other agricultural crops [17] (Figure 5).

\section{Conclusion}

Apart from the water consumption and the allelopathy nature, Eucalyptus, when compared with other trees, is known to have the fastest growth rate and supply fuelwood, charcoal, construction materials and other services. The plant also requires a minimum attention by the growers and can establish itself swiftly. It can grow in degraded lands. The plant can reproduce very easily through seed and coppicing can result in a good number of sprout outs to regenerate in a timely fashion. The plant is highly resistant to pest and disease and has also medicinal values to humans. Hence, numerous studies evidenced that the benefits of Eucalyptus outweighs the drawbacks. Therefore, if environmentalists and decision maker's collaborative efforts are geared towards the establishment of a proper management system for the growth and development of the Eucalyptus tree plantations, the tree can continue to combat the alarmingly growing deforestation rate of the native plant biodiversity resources of the country and beyond.

\section{References}

[1] USDA (United States Department of Agriculture) (2016) US Forest Service. http://www.fs.fed.us/managing-land/urban-forests/ucf

[2] Zegeye, H. (2010) Environmental and Socio-Economic Implications of Eucalyptus in Ethiopia. In: Gil, L., Tadesse, W., Tolosana, E. and López, R., Eds., Proceedings of the Conference on Eucalyptus Species Management, History, Status and Trends in Ethiopia, Ethiopian Institute of Agricultural Research, Addis Ababa, 184-205.

[3] Wangchuk, S., Siebert, S. and Belsky, J. (2013) Fuelwood Use and Availability in Bhutan: Implications for National Policy and Local Forest Management. Springer Science+Business Media, New York.

[4] Broadhead, J.S., Bahdon, J. and Whiteman, A. (2001) Past Trends and Future Prospects for the Utilization of Woo d for Energy. Global Forest Products Outlook Study Working Paper No. 5. FAO, Rome.

[5] FAO (2011) Eucalyptus in East Africa, Socio-Economic and Environmental Issues, by Gessesse Dessie, Teklu Erkossa. Planted Forests and Trees Working Paper 46/E, Forest Management Team, Forest Management Division. FAO, Rome.

[6] Gledhill, D. (2008) The Names of Plants. 4th Edition, Cambridge University Press, Cambridge, p. 158. 
[7] Pohjonen, V. (1989) Establishment of Fuelwood Plantations in Ethiopia (Silva Cerelica Series). University of Joensuu, Joensuu.

[8] FAO (1988) The Eucalypt Dilemma. FAO, Forestry Department, Rome.

[9] Breitenbach, V. (1961) Exotic Trees in Ethiopia. Ethiopian Forestry Review, 2, 19-38.

[10] Mekonnen, Z. (2010) Community Opinion, Marketing and Current Debates on Eucalyptus. Proceeding for the Conference on Eucalyptus Management, History, Status and Trends in Ethiopia, Addis Ababa, 15-17 September 2010, 131-145.

[11] Madalcho, A.B. and Tefera, M.T. (2016) Management of Traditional Agroforestry Practices in Gununo Watershed in Wolaita Zone, Ethiopia. Forest Research, 5, 163. https://doi.org/10.4172/2168-9776.1000163

[12] WBSPP (Woody Biomass Strategic Planning Project) (2005) On CD. Addis Ababa.

[13] Teketay, D. (2000) Facts and Experiences on Eucalypts in Ethiopia and Elsewhere: Ground for making wise and informed decision. Walia, 21, 25-46.

[14] Kidanu, S. (2004) Using Eucalyptus for Soil and Water Conservation on the Highland Vertisols of Ethiopia. PhD Thesis, Wageningen University and Research Center, Wageningen.

[15] Pohjonen, V. and Pukkala, T. (1990) Eucalyptus Globulus in Ethiopian Forestry. Forest Ecology and Management, 36, 19-31. https://doi.org/10.1016/0378-1127(90)90061-F

[16] Mekonnen, Z., Kassa, H., Lemenh, M. and Campbell, B.M. (2007) The Role and Management of Eucalyptus in Lode Hetosa District, Central Ethiopia. Forest, Trees and Livelihoods, 17, 309-323. https://doi.org/10.1080/14728028.2007.9752606

[17] Getahun, A. (2002) Eucalyptus Farming in Ethiopia: The Case for Eucalyptus Woodlots in the Amhara Region. In: 2002 Bahir Dar Conference Proceedings, Ethiopian Society of Soil Science, Bahir Dar, 137-153.

\section{Submit or recommend next manuscript to OALib Journal and we will provide best} service for you:

- Publication frequency: Monthly

- 9 subject areas of science, technology and medicine

- Fair and rigorous peer-review system

- Fast publication process

- Article promotion in various social networking sites (LinkedIn, Facebook, Twitter, etc.)

- Maximum dissemination of your research work

Submit Your Paper Online: Click Here to Submit

Or Contact service@oalib.com 